\title{
CNS Toxicity of Immunotherapy
}

\author{
David Gorlin ${ }^{1}$, Rania Bilwani ${ }^{1}$, Saman Khan ${ }^{1}$, Maryam Gul' ${ }^{2}$ Muhammad H Imam ${ }^{3}$, and Ammar Chaudhry ${ }^{4 *}$ \\ ${ }^{1}$ Research Intern, Department of Diagnostic Radiology, City of Hope National Cancer Center, Los Angeles, California, USA \\ ${ }^{2}$ Amaze Research Foundation, Los Angeles, California, USA \\ ${ }^{3}$ Florida Cancer Specialists, Orlando, Florida, USA \\ ${ }^{4}$ Director, Precision Imaging Lab, Director of Imaging Informatics Research, Department of Diagnostic Radiology City of Hope National Cancer Center, \\ Los Angeles, California, USA
}

*Corresponding author: Ammar A Chaudhry, Director, Precision Imaging Lab, Director of Imaging Informatics Research, Department of Diagnostic Radiology, City of Hope National Cancer Center, , Los Angeles, California, USA, E-mail: achaudhry@coh.org

Received: 13 May, 2020 | Accepted: 18 Jun, 2020 | Published: 24 Jun, 2020

Citation: Gorlin D, Bilwani R, Khan S, Gul M, Imam MH, et al. (2020) CNS Toxicity of Immunotherapy. Clin Res Open Access 6(2): dx.doi. org/10.16966/2469-6714.157

Copyright: (C) 2020 Gorlin D, et al. This is an open-access article distributed under the terms of the Creative Commons Attribution License, which permits unrestricted use, distribution, and reproduction in any medium, provided the original author and source are credited.

Keywords: Immunotherapy; Imaging biomarkers; CNS toxicity

\section{Introduction}

Recent advancements in cancer treatment have significantly contributed to the improvement of the cancer mortality rate and the overall relative survival rate [1]. Immunotherapy has emerged as a promising treatment option alongside surgery, chemotherapy, and radiotherapy. Immunotherapy is a unique treatment strategy that works by engaging the immune system to elicit anti-tumor response. In recent years, Immune Checkpoint Inhibitors (ICI) agents alone or in combination with other treatment options have demonstrated the capacity to eliminate cancers with greater efficacy and tolerability than previous standard-of-care therapies [2]. Thus, ICI and cell-based immunotherapies have revolutionized the treatment of a range of hematological and solid cancer types (Table 1).

Despite novel insight into the mechanics of successful immunotherapy, a number of obstacles hinder optimal clinical performance, including a broad variety of Immune-Mediated Adverse Events (IMAE). To maintain durability against tumors, immunomodulators must elicit a powerful immune response. Consequently, the heightened immune activity may lead to inflammation, triggering an autoimmune response which results in damage to healthy cells and induces adverse events across the body $[19,20]$. The frequency and severity of IMAEs vary by site and type of immunotherapy. According to the National Cancer Institute of the National Institutes of Health's Common Terminology Criteria for Adverse Events (version 5.0) [21], the severity of immune-mediated adverse events are classified as: Table 2.

IMAEs in the Central Nervous System (CNS) present a significant obstacle for the continuation of treatment and favorable patient outcomes. Immunotherapies can impair the regulatory mechanisms in the CNS that protect it from excessive immune responses, which may cause severe neuronal damage. These toxicities can escalate rapidly and without proper management can be fatal. The incidence of IMAEs in the CNS varies by immunotherapy type, with highest reported rates in CAR T-cell therapy (0-87\%) [22] and ICI therapy (3.8-12\%) [23]. The pathogenesis of immune-mediated CNS toxicities is an active area of research and has been associated with: blood-brain barrier disturbance, excessive cytokine concentration in the blood and cerebrospinal fluid, and endothelial activity $[22,24]$.

Improved understanding of the pathogenesis of CNS toxicities may reveal biomarkers capable of assessing risk and severity, as well as distinguishing CNS toxicity from tumor-related damage. In addition, predictive biomarkers could lead to earlier detection and prevent treatment-mediated toxicities. While model biomarkers have been explored (e.g. IL6 and MCP-1 [24], lymphodepletion [25], IL15, IL10, and EFG [26]), their significance and reliability require further validation. Noninvasive biomarkers have many advantages over traditional invasive techniques, and can serve as a guide for clinicians to describe the nature of immune-mediated CNS toxicity and track its progress.

IMAEs in the CNS can be noninvasively diagnosed and monitored using conventional ${ }^{18} \mathrm{~F}$-fluorodeoxyglucose (FDG), ${ }^{18}$ Fluoro-3'deoxythymidine (FLT), or ${ }^{18}$ Fluoro-ethyl-L-tyrosine (FET) Positron Emission Tomography/Computed Tomography (PET/CT); contrast enhanced CT, and Magnetic Resonance Imaging (MRI). FDG PET/ $\mathrm{CT}$ is the most commonly utilized modality to analyze IMAEs. Because FDG radiotracer is a glucose analogue, uptake values will increase in both inflammatory cells and tumor; allowing it to detect and localize IMAEs in the CNS [27]. MRI is the favored imaging modality for IMAEs in the CNS because of higher spatial resolution and soft tissue resolution, relative to PET/CT [28,29]. Radiological patterns of IMAEs may overlap with other pathologies, and it is essential to differentiate IMAEs from tumor-related damage or other 
Table 1: FDA approved indications of immunotherapy.

\begin{tabular}{|c|c|}
\hline Type of Immunotherapy & FDA approved indications \\
\hline \multicolumn{2}{|l|}{ Immune Checkpoint Inhibitors } \\
\hline \multicolumn{2}{|l|}{ Anti PD-1 } \\
\hline Pembrolizumab [3] & Non-Small Cell Lung Cancer, Head and Neck Squamous Cell Carcinoma, Melanoma \\
\hline Nivolumab [4] & Small Cell Lung Cancer, Advanced Renal Cell Carcinoma, Classical Hodgkin Lymphoma \\
\hline Cemiplimab [5] & Cutaneous Squamous Cell Carcinoma \\
\hline \multicolumn{2}{|l|}{ Anti PD-L1 } \\
\hline Atezolizumab [6] & Non-Small Cell Lung Cancer, Advanced Renal Cell Carcinoma, Triple-Negative Breast Cancer \\
\hline Avelumab [7] & Advanced Renal Cell Carcinoma, Urothelial Carcinoma, Merkel Cell Carcinoma \\
\hline Durvalumab [8] & Non-Small Cell Lung Cancer, Urothelial Carcinoma \\
\hline \multicolumn{2}{|l|}{ Anti CTLA-4 } \\
\hline Ipilimumab [9] & Melanoma \\
\hline Combination of Ipilimumab and Nivolumab [9] & $\begin{array}{l}\text { Hepatocellular carcinoma, Advanced renal cell carcinoma, Melanoma, Microsatellite instability- } \\
\text { high (MSI-H) or mismatch repair deficient (dMMR) metastatic colorectal cancer }\end{array}$ \\
\hline \multicolumn{2}{|l|}{ CAR T-cell Therapy } \\
\hline \multicolumn{2}{|l|}{ Anti-CD19 } \\
\hline Tisagenlecleucel [10] & $\begin{array}{l}\text { B-cell acute lymphoblastic leukemia, Diffuse large B-cell lymphoma, High grade B-cell lymphoma, } \\
\text { DLBCL arising from follicular lymphoma }\end{array}$ \\
\hline Axicabtageneciloleucel [11] & $\begin{array}{l}\text { Diffuse large B-cell lymphoma, Primary mediastinal large B-cell lymphoma, High grade B-cell } \\
\text { lymphoma, DLBCL arising from follicular lymphoma }\end{array}$ \\
\hline Anti-CD22 [12] & Currently under investigation for B-cell acute lymphoblastic leukemia \\
\hline IL13R $\alpha 2[13]$ & Currently under investigation for Glioblastoma \\
\hline Anti-BCMA [14] & Currently under investigation for relapsed or refractory multiple myeloma \\
\hline Anti-CD123 [15] & Currently under investigation for acute myeloid leukemia \\
\hline \multicolumn{2}{|l|}{ Vaccines } \\
\hline Sipuleucel-T [16] & Metastatic castrate resistant (hormone refractory) prostate cancer \\
\hline BCG Live [17] & Carcinoma in situ (CIS) of the urinary bladder, papillary tumors \\
\hline \multicolumn{2}{|l|}{ NK cell } \\
\hline CAR-NK-92 [18] & $\begin{array}{l}\text { Currently under investigation for acute myeloid leukemia, glioblastoma, prostate cancer, and } \\
\text { ovarian cancer }\end{array}$ \\
\hline
\end{tabular}

Table 2: Common terminology criteria for adverse events (version 5.0) [21].

\begin{tabular}{|c|c|c|}
\hline Grade & Classifications & Severity \\
\hline 1 & $\begin{array}{c}\text { Asymptomatic or mild symptoms } \\
\text { Clinical or diagnostic observations only } \\
\text { No intervention required }\end{array}$ & Mild \\
\hline 2 & $\begin{array}{l}\text { Minimal, local or noninvasive intervention required } \\
\text { Limits activities of daily life }\end{array}$ & Moderate \\
\hline 3 & $\begin{array}{c}\text { Hospitalization required } \\
\text { Disabling or limiting self care activities of daily life }\end{array}$ & $\begin{array}{l}\text { Severe/medically significant but not immediately } \\
\text { life-threatening }\end{array}$ \\
\hline 4 & Urgent intervention required & Severe, life-threatening \\
\hline 5 & Death related to adverse events & Extremely severe, life-threatening \\
\hline
\end{tabular}

potential conditions caused by infections, metabolism, or neoplastic and paraneoplastic complications [30].

Majority of IMAEs in the CNS develop within the first few months of immunotherapy; however, they can present late or possibly after discontinuation [20,23]. Recognition and management are crucial to prevent or de-escalate any IMAEs. For grade 2 and above symptoms, treatment should be withheld. Grade 3 and above symptoms generally require discontinuation of treatment [28]. Immunosuppressive corticosteroid drugs are the recommended treatment for IMAEs; however, when administered simultaneously with immunotherapy, corticosteroids reduce its efficacy [28]. The reversibility of IMAEs are determined by their pathogenesis. Even after discontinuation of treatment, IMAEs may persist [20]. Reversibility patterns displayed on imaging modalities can help improve patient management. According to the Immunotherapy Response Assessment in Neuro-Oncology guidelines, clinicians may consider resuming immunotherapy treatment given that follow-up images confirm safety and patients show positive results with acceptable toxicity [28]. 
In this review, we summarize the immune-mediated CNS toxicities, with primary focus on their clinical symptoms, biomarkers, and radiological appearance. By examining the IMAEs in the CNS according to the type of immunotherapy, we hope to assist clinicians in earlier recognition and improved patient management.

\section{Immune Checkpoint Inhibitors}

The use of ICIs for immunotherapy has revolutionized cancer treatment because of its efficacy in improving prognosis. Ipilimumab is an ICI that targets cytotoxic $\mathrm{T}$ lymphocyte-associated antigen 4 (CTLA-4), which limits $\mathrm{T}$ cell activation by competing with the costimulatory protein $\mathrm{CD} 28$ for binding [31]. Other ICIs have different targets, such as programmed cell death receptor (PD-1) or its ligand (PD-L1) (Table 1). T cell immunoglobulin and mucin domaincontaining protein 3 (TIM-3), lymphocyte-activation gene 3 (LAG-3) and $\mathrm{V}$ domain Ig suppressor of $\mathrm{T}$ cell activation (VISTA) are still being studied as targets [32]. IMAEs associated with the use of ICIs have since been discovered and are being investigated.

Although Neurological Adverse Events (NAEs) are rare, they are still a relevant area of research because of the significant possibility of morbidity and mortality. Various CNS toxicities are associated with ICIs (Table 3), most commonly with ipilimumab [31]. Toxicity should be managed by interrupting the use of ICIs and using corticosteroid immunosuppression as needed [37]. This should be followed by other $\mathrm{T}$ cell suppressors and intravenous immunoglobulin (IVIG) or plasmapheresis for severe toxicities (grade 3 and higher) [38]. Imaging plays a critical role in identifying toxicity; early diagnosis and intervention of Paraneoplastic Syndromes (PNSs) can help prevent irreversible effects [32]. Diagnostic specificity is essential in differentiating between aseptic meningitis, which can show leptomeningeal enhancement on MRI, and leptomeningeal disease, which has sulcal enhancement on T1 contrast-enhanced and FLAIR sulcal hyperintensity [31].

Novel ICI-based combinatorial approaches in cancer treatment have presented the best possible patient outcomes for a number of cancers to date. By combining ICI with standard treatments and other immunotherapies, cancer cells are eliminated via cytotoxic and cytostatic mechanisms as well as the enhanced immune response; increasing response rates to over 50\% [39]. The considerable potential of synergistic combinatorial approaches is exemplified by outcomes in patients with Non-Small Cell Lung Cancer (NSCLC). When administered anti-PD1 antibodies in addition to chemotherapy, the overall response rate of patients with NSCLC rose from 19\% to $48 \%$ with no significant increase in adverse events (ClinicalTrials.gov Identifier: NCT02578680). ICIs demonstrate the ability to optimize the efficacy of standard treatment options, including chemotherapy, radiotherapy, and radiotherapy.

Blocking CTLA-4, PD1 and PD-L1 antibodies allows the immune system to bypass several tumor evasion mechanisms simultaneously, resulting in increased infiltration, activation and cytokine production [39]. This treatment strategy overcomes immunosuppressive mechanisms in the tumor microenvironment and augments cancer cell elimination. However, as a consequence of compounded autoimmunity, the occurrence of immune-mediated AEs (Table 3) increases to approximately $12 \%$ [30].

\section{Car T Cells}

Chimeric Antigen Receptor (CAR) T cell therapy is a type of gene therapy designed to recruit the body's own immune system to respond to proliferating tumor cells. This is accomplished through ex vivo augmentation of antigen receptors found on autologous $\mathrm{T}$ cells, which are cultured and transplanted back into the patient [40]. Since FDA approval in 2017, commercially available CAR T-Cells have significantly improved the management of hematological malignancies and have garnered CMS national determination coverage as of September 2019. Efforts to adapt this treatment to a myriad of other tumor types is currently being investigated.

The first FDA approved commercial CAR T-Cell therapy used genetically modified chimeric antigen receptors that target CD-19 positive malignant B-Cells to treat refractory acute lymphoblastic leukemia $[41,42]$. Investigators have since demonstrated its variegated therapeutic applications in the treatment of other CD 19 positive malignancies such as Diffuse Large B Cell Lymphoma [43-45]. CD19 was chosen as a target for therapy due to its expression early in the B cell lineage [40], and while anti-CD-19 CAR T-cell therapy has demonstrated a high rate of remission, BCMA and antiCD22 CAR T-cells have also been developed as a next line therapy in situations

Table 3: Immune-mediated CNS toxicities associated with immune checkpoint inhibitors.

\begin{tabular}{|c|c|c|c|}
\hline Toxicity & Toxicity grade & Imaging Features & Symptoms \\
\hline Hypophysitis & $3-4[33]$ & $\begin{array}{c}\text { MRI: Enlargement of pituitary gland/stalk and } \\
\text { hypoenhancing nodules; heterogeneous enhancement } \\
\text { [31] }\end{array}$ & $\begin{array}{l}\text { Headaches, dizziness, diplopia, loss of peripheral } \\
\text { vision and fatigue, nausea/vomiting [31] } \\
\text { hyponatremia (diabetes insipidus) or multiple } \\
\text { endocrinopathy }\end{array}$ \\
\hline $\begin{array}{l}\text { Encephalopathy/ } \\
\text { encephalitis }\end{array}$ & $3-4[34]$ & $\begin{array}{l}\text { MRI: normal in } 1 / 2 \text { patients; medial temporal T2 } \\
\text { hyperintensity, negative CSF [32] enhancement of gray } \\
\text { matter or cortex; white matter } t 2 \text { hyperintensities }\end{array}$ & $\begin{array}{c}\text { Confusion, decreased arousal, language deficit, } \\
\text { seizures, gait instability, headaches, fevers, and } \\
\text { hallucinations [32] }\end{array}$ \\
\hline Aseptic meningitis & $3-4[34]$ & $\begin{array}{c}\text { MRI: Typically normal imaging but you may see } \\
\text { leptomeningeal enhancement, CSF analysis may show } \\
\text { lymphocytic pleocytosis [32] }\end{array}$ & $\begin{array}{l}\text { Worsening headache, photophobia, neck stiffness, } \\
\text { possible fever, vomiting but normal CNS function } \\
{[32]}\end{array}$ \\
\hline CNS demyelination & $\begin{array}{l}3-4 \\
{[35]}\end{array}$ & $\begin{array}{l}\text { T2 hyperintensity of white matter tracts +/- } \\
\text { enhancement (multiple sclerosis type pattern) [32] }\end{array}$ & Confusion [32] \\
\hline $\begin{array}{l}\text { Paraneoplastic } \\
\text { syndrome }\end{array}$ & $\begin{array}{c}3-4 \\
{[34]}\end{array}$ & $\begin{array}{c}\text { MRI: Normal or T2 hyperintensity in bilateral medial } \\
\text { temporal lobe [32] }\end{array}$ & $\begin{array}{l}\text { Various neurological symptoms including slurred } \\
\text { speech and vision problems [36] }\end{array}$ \\
\hline Transverse myelitis & & $\begin{array}{c}\text { Focal T2 abnormality and CSF lymphocytosis [32] } \\
\text { Spine MRI T2 intense lesion, T1C signal abnormality } \\
\text { [31] }\end{array}$ & Motor, sensory, and/or autonomic dysfunction [31] \\
\hline
\end{tabular}

Citation: Gorlin D, Bilwani R, Khan S, Gul M, Imam MH, et al. (2020) CNS Toxicity of Immunotherapy. Clin Res Open Access 6(2): dx.doi. 
where relapse occurs. This has been of particular benefit in cases of pediatric B-ALL [12,46] and in Multiple Myeloma [14].

With positive results in hematologic malignancies, there is increasing interest in implementing CAR T-Cell therapy towards treating solid tumors as well. Clinical trials demonstrating the benefit IL13Ra2 CAR T-cells in the treatment of glioblastoma are currently underway [13]. Furthermore, HER-2 specific CAR T-Cells have been successfully designed to target breast cancer metastatic to the brain [47], and phase 1 clinical trials have begun to investigate their safety and efficacy in patient care (ClinicalTrials.gov Identifier: NCT03696030).

In addition to CAR T-Cell therapies, Bispecific T Cell engagers (BITE) such as blinatumomab have been developed to recruit T cells in a similar fashion without the demanding workflow of gene therapy. Blinatumomab is a monoclonal antibody that shares affinity for both CD19 on malignant B cells and CD3 on cytotoxic T-cells generating a similar mechanism of action as antiCD 19 CAR T-cells. Bispecific T-Cell engagers are often considered alongside CAR T-cells given their overlap in treatment indication, mechanism of action, and toxicity management [48].

Even in their nascent clinical trials, each of these breakthrough immunotherapies has exhibited similar toxicities (Table 4) that complicated patient care $[41,43,45,49]$. Within two to six days of receiving treatment, patients would report a cluster of symptoms that have become known as cytokine release syndrome, or CRS [50-53].

The pathogenesis of CRS is best described by the duly named cytokine storm that results from the rapid activation of the immune system flooding the blood circulation with TNF alpha, IL1, IL6, IL8, IL 10 , and interferon gamma $[52,54,55]$. Uncontrolled, severe CRS can result in hypotension, organ failure, and death (Table 4). However, approval to use anti IL6 tocilizumab for CRS has lowered its incidence and severity [51]. Glucocorticoids are also used as a second line when tocilizumab fails. There are ongoing studies investigating the timing of tocilizumab and its efficacy in treating CRS specifically in B cell ALL (ClinicalTrials.gov number, NCT02906371); however, neither glucocorticoids nor anti IL6 therapy have been reported to significantly effect treatment response.

The second most common complication of Cellular Therapy is neurotoxicity, and is experienced by $40-60 \%$ of patients [48]. Headaches caused by encephalopathy were commonly reported and believed to be included in the presentation of CRS, becoming known as cytokine release encephalopathy-syndrome $[27,56]$. However, further analysis revealed several patients have experienced varying degrees of neurotoxicity, sometimes in the absence of CRS, and so these

Table 4: ASBMT CRS consensus grading.

\begin{tabular}{|c|l|}
\hline Grade & \multicolumn{1}{c|}{ CRS Parameter } \\
\hline 1 & Fever: Temperature $\geq 38^{\circ} \mathrm{C}$ \\
\hline 2 & $\begin{array}{l}\text { Fever: Temperature } \geq 38^{\circ} \mathrm{C} \\
\text { Hypotension: Does not require vasopressors } \\
\text { And / or hypoxia: Requires low- flow oxygen delivery }\end{array}$ \\
\hline 3 & $\begin{array}{l}\text { Fever: Temperature } \geq 38^{\circ} \mathrm{C} \\
\text { Hypotension: Requires single vasopressor therapy } \\
\text { (vasopressin) } \\
\text { And / or hypoxia: Requires high- flow oxygen delivery }\end{array}$ \\
\hline 4 & $\begin{array}{l}\text { Fever: Temperature } \geq 38^{\circ} \mathrm{C} \\
\text { Hypotension: Multiple vasopressor therapy without } \\
\text { vasopressin } \\
\text { And / or hypoxia: Requires positive pressure oxygen therapy }\end{array}$ \\
\hline
\end{tabular}

discrete symptoms have become known as Immune Effector CellAssociated Neurotoxicities (ICANs; Table 5) [48,51]. Furthermore, in the phase II trial investigating the use of Axicabtagene ciloleucel in large B-Cell Lymphoma, specific biomarkers such as IL-2, GM-CSF, and ferritin were exclusively detected in the presence of grade 3 or greater neurological events [43]. This argued for classifying ICANs independently of CRS.

There have been several different grading systems developed specifically for neurological toxicity, which unfortunately have led to inconsistencies throughout the literature [51]. The most accepted diagnostic grading system today is the consensus grading scale outlined by the American Society for Transplant and Cellular Therapy [53] (Table 5). This incorporates either a revised version of the CARTOX-10 neurological exam now known as Immune Effector Cell Encephalopathy (ICE) (Table 6) grading tool, or the Cornell Assessment of Pediatric Delirium (CAPD) for children under the age of 12. Grading also considers seizure evaluation, as well as biomarkers to determine the severity of ICANS. Grade 5 neurotoxicity by convention is considered to result in death.

Neurotoxicity is an on-target effect of CAR-T cell therapy, and reported in all varieties of treatment [40]. CAR- T cell expansion in the peripheral blood is a strong prognostic indicator of treatment response $[43,45]$. Independently, both the peak of CAR T-Cell expansion [43] and severity of CRS [26] are significantly associated with the onset of grade 3 or higher neurologic events. Neurotoxicity by itself is managed empirically through supportive care. In long term follow up of patients with ICANs, neurotoxicity is not correlated with CNS progression of disease and irreversible damage is very rarely observed in patients who have recovered $[48,51]$.

Radiographically, MRI of the brain (Table 7) tends to be normal during low grade neurological events, although patterns of vasogenic edema, multifocal microhemorrhage, and leptomeningeal enhancement have been demonstrated in those who have experienced moderate-to-severe neurotoxicity $\geq$ grade $3[25,26,57]$. Overall, these patterns have been found to be similar to those characteristic of posterior reversible encephalopathy syndrome (PRES) [26,57]. In some cases, local and diffuse cerebral Radiographically, MRI of the brain (Table 7) tends to be normal during low grade neurological events, although patterns of vasogenic edema, multifocal microhemorrhage, and leptomeningeal enhancement have been demonstrated in those who have experienced moderate-to-severe neurotoxicity $\geq$ grade 3 $[25,26,57]$. Overall, these patterns have been found to be similar to those characteristic of posterior reversible encephalopathy syndrome (PRES) [26,57]. In some cases, local and diffuse cerebral edema have been identified that result in cortical damage or death in the most severe cases of neurotoxicity. There have also been reports of transient exacerbation of previously identified lesions present at the start of treatment, which include damage incurred during chemotherapy or radiation. There currently is a lack of high-powered controlled studies investigating these neuroimaging patterns. This has warranted the call by many to further investigate the role of neuroimaging in the standard of care for patients undergoing cellular therapies [58-60].

There remains to be an ongoing discussion regarding the pathogenesis of ICANS. Analysis of samples of CSF biopsied through lumbar puncture during high grade neurologic events have revealed elevated protein levels, consistent with disruption of the blood brain barrier $[25,26]$. Further analysis of biomarkers in the CSF also revealed abnormally high ratios of inflammatory cytokines such as IL6 compared to peripheral circulation, suggesting an increased de novo production within the CNS. NDMA agonists have also been

Citation: Gorlin D, Bilwani R, Khan S, Gul M, Imam MH, et al. (2020) CNS Toxicity of Immunotherapy. Clin Res Open Access 6(2): dx.doi. 
Table 5: ASBMT ICANS consensus for adults.

\begin{tabular}{|c|c|c|c|c|c|c|}
\hline Grade & Motor Findings & Elevated ICP/ cerebral Edema & Seizure Severity & Arousal level & $\begin{array}{c}\text { ICE score } \\
\text { age } \geq 12 \text { years }\end{array}$ & $\begin{array}{c}\text { CAPD score } \\
\text { age }<12 \text { years }\end{array}$ \\
\hline 1 & None & None & None & $\begin{array}{c}\text { Spontaneously } \\
\text { awakens }\end{array}$ & $7-9$ & $1-8$ \\
\hline 2 & None & None & None & Aroused by voice & $3-6$ & $1-8$ \\
\hline 3 & None & Focal/ local edema on MRI & $\begin{array}{l}\text { Any nonlife -threatening } \\
\text { clinical seizure } \\
\text { or nonconvulsive seizure } \\
\text { on EEG }\end{array}$ & $\begin{array}{l}\text { Arousal requires } \\
\text { somatosensory } \\
\text { stimulation }\end{array}$ & $0-2$ & $\geq 9$ \\
\hline 4 & $\begin{array}{l}\text { Focal impairment } \\
\text { of voluntary } \\
\text { movement (e.g. } \\
\text { hemiparesis or } \\
\text { paraparesis) }\end{array}$ & $\begin{array}{l}\text { Diffuse cerebral edema on MRI; } \\
\text { decerebrate or decorticate } \\
\text { posturing; or cranial nerve } \\
\text { VI palsy; or papilledema; or } \\
\text { Cushing's triad }\end{array}$ & $\begin{array}{l}\text { Prolonged life-threatening } \\
\text { seizure lasting more than } 5 \\
\text { min; ore repetitive seizures } \\
\text { without return to baseline }\end{array}$ & $\begin{array}{l}\text { Unarousable, } \\
\text { or requires } \\
\text { intense physical } \\
\text { stimulation. Coma }\end{array}$ & Unresponsive & Unresponsive \\
\hline
\end{tabular}

Table 6: ASBMT ICANS consensus grading: encephalopathy assessment tools.

\begin{tabular}{|c|c|c|}
\hline CAPD: for children age $<12$ years & ICE: age $\geq 12$ years & \\
\hline \multicolumn{2}{|c|}{$\begin{array}{l}\text { Rate each of the following from } 0-4,0 \text { being always } 4 \text { being } \\
\text { never }\end{array}$} & Orientation: Can recall the month, year, hospital, or city 4 points \\
\hline Eye Contact & Restlessness & Naming: Demonstrates the ability to name up to 3 objects in the room objects 3 points \\
\hline Purposeful actions & Inconsolable & Follows Directions: Performs a simple task on command: 1 point \\
\hline Awareness of surroundings & Activate while awake & Writing: Demonstrates ability to write a complete sentence: 1 point \\
\hline Communicates wants and needs & Extended response time & Attention: Counting backwards by 10 from 100: 1 point \\
\hline
\end{tabular}

Table 7: ICANs Associated with CAR T-cell Therapy.

\begin{tabular}{|c|c|c|c|}
\hline Neurotoxicity & Grade & Neuroimaging Pattern & Source \\
\hline Limbic encephalitis & $3-4$ & $\begin{array}{l}\text { MRI: T2 Flair changes in bilateral mesial temporal lobes, but also occasionally found in } \\
\text { frontal and parietal lobes, and cerebellum }\end{array}$ & [59] \\
\hline Cytotoxic edema & $3-4$ & MRI: Cortical diffusion restriction on DWI and cortical swelling on FLAIR & {$[25,57]$} \\
\hline Cortical injury & $3-4$ & $\begin{array}{l}\text { MRI: One patient with patient with cytotoxic edema reportedly progressed to have } \\
\text { T1 hyperintensities in the cortical ribbon } 10 \text { days later. Another pediatric patient with } \\
\text { diffusion restriction in the right occipital demonstrated occipital hypometabolism on FDG } \\
\text { PET } 10 \text { months following acute injury }\end{array}$ & {$[25,57]$} \\
\hline Vasogenic edema & $3-5$ & $\begin{array}{l}\text { MRI: FLAIR hyperintensity in bilateral thalami and brainstem (midbrain, pons, medulla, } \\
\text { basal ganglia, extreme capsule, brachium pontis). No diffusion restriction. Punctate } \\
\text { hemorrhage T2 dark lesions }\end{array}$ & {$[25,26,57]$} \\
\hline $\begin{array}{l}\text { Transient lesions of the } \\
\text { splenium of the corpus } \\
\text { collosum }\end{array}$ & $3-5$ & MRI: Restricted diffusion on DWI and T2/ FLAIR hyperintensity & {$[26,59]$} \\
\hline Global edema & 5 & MRI: Blurring of gray-white junctions and slit- like ventricles on FLAIR imaging & [25] \\
\hline Aseptic meningitis & 5 & MRI: Diffuse leptomeningeal enhancement T2 hyperintensities & [25] \\
\hline
\end{tabular}

hypothesized to contribute to an increase in blood brain permeability and neurological symptoms [26].

Many of the toxicities reviewed have been reported in the use of anti CD19 CAR T-Cells, as these are the most widely used in current practice. There has been some debate as to whether variability in the costimulatory domain of anti CD19 CAR T-Cells could increase neurotoxicity. Originally, higher incidence of fatal cerebral edema occurred in anti CD19 CAR T-Cells containing CD28 co-stimulatory domains than in those containing $41 \mathrm{BB}$ domains [42,43]. However, there is insufficient evidence to suggest one is more toxic than the other. ICANs have been reported to be common among all types of CAR T-Cell therapy, although the incidence of severe high-grade neurological events is less common in those other than anti CD-19. For example, cerebral edema has been reported in BCMA therapy, but this appears to be more rare in antiCD-22 CAR T-Cell therapy [40]. In the treatment of solid tumors, grade 1-2 neurotoxicity was reported in treatment of glioblastoma with IL13Ra2 CAR T-cells [13]. An appreciable increase in inflammatory cytokine concentration in the CSF was consistent with other CAR T-cell therapies, although severe neurotoxicity has yet to be reported. 
CAR T-cell and other immune effector cellular based therapies is a rapidly emerging approach to treating cancer, with neurotoxicity being one of its most common side effects. Most common signs of neurotoxicity are headaches and/or disorientation. The role biomarkers such as CSF analysis and neuroimaging patterns can play an important role in the management of this neurotoxicity. Moving forward, standardized toxicity grading and diagnostic protocols will be impetrative in understanding neurotoxicity pathogenesis, prevention, and management.

\section{Stem Cell Therapy}

Hematopoietic Stem Cell Transplants (HSCT) have contributed greatly to the treatment of cancer, but the pre-conditioning required consists of chemotherapy and/or radiotherapy, which can lead to various CNS toxicities such as severe encephalopathy, posterior reversible encephalopathy syndrome (PRES), and transverse myelitis [61]. HSCT has pioneered concepts of stem cell therapy as cancer treatment [62].

Induced Pluripotent Stem Cells (iPSCs) prevent adverse drug reactions by personalizing treatment specific to the patient. iPSCs can be used to generate anti-tumor $\mathrm{T}$ and Natural Killer (NK) lymphocytes. iPSCs are particularly advantageous due to their ability to be genetically modified, making them useful to a wider range of patients and cancers [63]. Because stem cells are unspecialized, they can theoretically differentiate into any cell type. Using this characteristic of iPSCs, scientists can noninvasively develop models of otherwise inaccessible tissues and cell types of organ systems such as the nervous system [64]. These organoids can be derived from iPSCs and serve as advanced, patient-specific models to help create personalized treatment by allowing researchers to determine the efficacy and toxicity of a particular drug [65].

The tumor-tropic nature of human Neural Stem Cells (NSCs) allows for direct therapeutic targeting of brain tumors without producing significant toxicity of normal brain tissue. A study by Portnow J, et al. found no dose-limiting toxicity associated with the intracranial administration of cytosine deaminase neural stem cells (CD-NSCs) into recurrent high grade glioma patients, proving NSCs to be a safe and effective brain tumor therapy [66].

\section{Dendritic Cell Therapy and Oncolytic Viral Therapy}

Dendritic Cell (DC) Vaccines have shown promise to aid in treating cancer. Not only are they effective, but they show minimal toxicity compared with other forms of immunotherapy. Dendritic cells are a unique type of immune cell that have the capacity to regulate both innate and adaptive immunity. DCs work by stimulating the body's immune system to kill cancer by recognizing cancer cell antigens and activating T-cells to eradicate the tumor. Under normal circumstances, DCs remain inactive until they are exposed to a stimulus such as inflammatory cytokines, microbial factors or endogenous alarmins. Once DCs are activated, they produce antigens to stimulate $\mathrm{T}$ cells on their major histocompatibility molecules. DC vaccines working against tumor antigens work to create an arm that aims to boost one's immune response through the use of immunotherapy. Cell-based therapies are emerging as a possible cancer cure because they have fairly low levels of toxicity as well as their ability to activate other immune modulators such as Natural Killer cells and T cells [67]. A study conducted at Rockefeller University, using ex vivo-generated monocyte-derived DCs, showed that neuropathy was one of the major toxicities associated with dendritic cell vaccines (ClinicalTrials.gov Identifier: NCT00345293).
Oncolytic viral therapy is another promising aid in cancer treatment. This immunotherapy has the advantage of the virus being able to infect and replicate in the tumor cells [68]. Neurotoxicities associated with this therapy include; dizziness, headache, Neurological disorder NOS, neuropathy, speech disorder, and syncope vasovagal. Patients also experienced vascular toxicities that consisted of flushing, hemorrhage, hypotension, and thrombosis (ClinicalTrials. gov Identifier: NCT00408590). Causing similar blood brain barrier disruption very novel approaches in curing cancer. These mechanisms overlap with some other treatments but some are nonspecific such as neuropathy. While some of these treatments overlap with ones previously mentioned, the appearance of neuropathy raises some questions about the on target effects of oncolytic viral therapy.

\section{Conclusion}

While immunotherapy presents the opportunity to eliminate cancers with great efficacy, the non-specific, hyperactive immune responses may target self-antigens and inflammatory cytokines. IMAEs in the CNS can cause serious cognitive and physiological impairments, posing limitations that undermine immunotherapy's success in clinical trials. Taking adverse events into consideration, patients should be closely monitored for clinical symptoms and suspicious radiographic abnormalities. PET/CT, CT, and MRI are readily available imaging modalities that can noninvasively identify IMAEs and display biomarkers, which may allow clinicians to describe their grade and reversibility. Early case series have shown positive MRI findings in patients with moderate-to-severe CNS toxicities. As such, clinicians can use imaging as a guide to make informed decisions regarding patient management, especially in critically ill patients. Depending on grade and reversibility of the IMAEs, clinicians may need to interrupt the immunotherapy dose schedule and/or administer corticosteroids to prevent the effects of the adverse events from outweighing the benefits derived from the treatment. Until progress is made in identifying the safest targets for antigen-specific cancer immunotherapies, early recognition and management of IMAEs in the CNS can prevent patient suffering and improve patients' quality of life.

\section{References}

1. Siegel RL, Miller KD, Jemal A (2020) Cancer statistics, 2020. CA: A Cancer J Clinicians 70: 7-30.

2. Kruger S, Ilmer M, Kobold S, Cadilha BL, Endres S, et al. (2019) Advances in cancer immunotherapy 2019-latest trends. J Exp Clin Cancer Res 38: 268.

3. US Food and Drug Administration (2019) Reference ID: 4389012.

4. US Food and Drug Administration (2019) OPDIVO (nivolumab) Label.

5. US Food and Drug Administration (2018) Libtayo (cemiplimab).

6. US Food and Drug Administration (2019) TECENTRIQ (atezolizumab).

7. US Food and Drug Administration (2019) BAVENCIO (avelumab).

8. US Food and Drug Administration (2018) Reference ID: 4223035.

9. US Food and Drug Administration (2018) Reference ID: 4289391.

10. US Food and Drug Administration (2019) KYMRIAH (tisagenlecleucel).

11. US Food and Drug Administration (2018) YESCARTA (axicabtageneciloleucel).

12. Fry TJ, Shah NN, Orentas RJ, Stetler-Stevenson $M$, Yuan $C M$, et al. (2018) CD22-targeted CAR T cells induce remission in B-ALL that is naive or resistant to CD19-targeted CAR immunotherapy. Nat Med 24: 20-28. 
13. Brown CE, Alizadeh D, Starr R, Weng L, Wagner JR, et al. (2016) Regression of Glioblastoma after Chimeric Antigen Receptor T-Cell Therapy. N Engl J Med 375: 2561-2569.

14. Raje N, Berdeja J, Lin Y, Siegel D, Jagannath S, et al. (2019) AntiBCMA CAR T-Cell Therapy bb2121 in Relapsed or Refractory Multiple Myeloma. N Engl J Med 380: 1726-1737.

15. Testa U, Pelosi E, Castelli G (2019) CD123 as a Therapeutic Target in the Treatment of Hematological Malignancies. Cancers (Basel) 11: 1358.

16. US Food and Drug Administration (2019) PROVENGE (sipuleucel-T).

17. US Food and Drug Administration (2009) BCG LIVE (FOR INTRAVESICAL USE) TICE ${ }^{\circledR}$ BCG.

18. (2019) Natural killer cells for cancer immunotherapy: a new CAR is catching up. EBioMedicine 39: 1-2.

19. Willis MD, Robertson NP (2019) Neurotoxicity of novel cancer immunotherapies. J Neurol 266: 2087-2089.

20. Blackmon JT, Viator TM, Conry RM (2016) Central nervous system toxicities of anti-cancer immune checkpoint blockade. J Neurol Neuromed 1: 39-45.

21. US Department of Health and Human Services, National Institutes of Health, National Cancer Institute (2017) Common Terminology Criteria for Adverse Events (CTCAE) Version 5.0.

22. Yáñez L, Sánchez-Escamilla M, Perales MA (2019) CAR T Cell Toxicity: Current Management and Future Directions. Hemasphere 3: e186.

23. Haanen JBAG, Carbonnel F, Robert C, Kerr KM, Peters S, et al. (2017) Management of toxicities from immunotherapy: ESMO Clinical Practice Guidelines for diagnosis, treatment and follow-up. Ann Oncol 28(suppl_4): iv119-iv142.

24. Gust J, Taraseviciute A, Turtle CJ (2018) Neurotoxicity Associated with CD19-Targeted CAR-T Cell Therapies. CNS Drugs 32: 1091-1101.

25. Gust J, Hay KA, Hanafi LA, Li D, Myerson D, et al. (2017) Endothelial Activation and Blood-Brain Barrier Disruption in Neurotoxicity after Adoptive Immunotherapy with CD19 CAR-T Cells. Cancer Discov 7: 1404-1419.

26. Santomasso BD, Park JH, Salloum D, Riviere I, Flynn J, et al. (2018) Clinical and Biologic Correlates of Neurotoxicity Associated with CAR T Cell Therapy in Patients with B-cell Acute Lymphoblastic Leukemia (B-ALL). Cancer Discov 8: 958-971.

27. Aide N, Hicks RJ, Le Tourneau C, Lheureux S, Fanti S, et al. (2019) FDG $\mathrm{PET} / \mathrm{CT}$ for assessing tumour response to immunotherapy : Report on the EANM symposium on immune modulation and recent review of the literature. Eur J Nucl Med Mol Imaging 46: 238-250.

28. Okada H, Weller M, Huang R, Finocchiaro G, Gilbert MR, et al. (2015) Immunotherapy response assessment in neuro-oncology: a report of the RANO working group. Lancet Oncol 16: e534-e542.

29. Sinigaglia M, Assi T, Besson FL, Ammari S, Edjlali M, et al. (2019) Imaging-guided precision medicine in glioblastoma patients treated with immune checkpoint modulators: research trend and future directions in the field of imaging biomarkers and artificial intelligence. EJNMMI Res 9: 78.

30. Fellner A, Makranz C, LotemM, Bokstein F, Taliansky A, et al. (2018) Neurologic complications of immune checkpoint inhibitors. J Neurooncol 137: 601-609.

31. Furtado VF, Melamud K, Hassan K, Rohatgi S, Buch K (2020) Imaging manifestations of immune-related adverse effects in checkpoint inhibitor therapies: A primer for the radiologist. Clinical imaging, 63: $35-49$.
32. Pan PC, Haggiagi A (2019) Neurologic Immune-Related Adverse Events Associated with Immune Checkpoint Inhibition. Current oncology Rep 21: 108.

33. Barroso-Sousa R, Barry WT, Garrido-Castro AC, Hodi FS, Min L, et al. (2018) Incidence of Endocrine Dysfunction Following the Use of Different Immune Checkpoint Inhibitor Regimens: A Systematic Review and Meta-analysis. JAMA Oncol 4: 173-182.

34. Graus F, Dalmau J (2019). Paraneoplastic neurological syndromes in the era of immune-checkpoint inhibitors. Nat Rev Clin oncol 16: 535-548.

35. Pillonel V, Dunet V, Hottinger AF, Berthod G, Schiappacasse L, et al. (2019) Multiple nivolumab-induced CNS demyelination with spontaneous resolution in an asymptomatic metastatic melanoma patient. J ImmunoTherapy Cancer 7: 336.

36. US Department of Health and Human Services, (2019) National Institute of Health. National Institute of Neurological Disorders and Stroke. Paraneoplastic Syndromes Information Page.

37. Postow M, Wolchok J (2020) Toxicities associated with checkpoint inhibitor immunotherapy. UpToDate. S. Shah, M. B. Atkins and H. J. West.

38. Chang VA, Simpson, DR, Daniels GA, Piccioni DE (2018) Infliximab for treatment-refractory transverse myelitis following immune therapy and radiation. J immunotherapy cancer 6: 153.

39. Seliger B (2019) Combinatorial Approaches With Checkpoint Inhibitors to Enhance Anti-tumor Immunity. Front Immunol 10: 999.

40. June $\mathrm{CH}$, Sadelain M (2018) Chimeric Antigen Receptor Therapy. N Engl J of Med 379: 64-73.

41. Maude SL, Frey N, Shaw PA, Aplenc R, Barrett DM, et al. (2014) Chimeric Antigen Receptor T Cells for Sustained Remissions in Leukemia. N Engl J of Med 371: 1507-1517.

42. Park JH, Rivière I, Gonen M, Wang X, Sénéchal B, et al. (2018) Long-Term Follow-up of CD19 CAR Therapy in Acute Lymphoblastic Leukemia. N Engl J of Med 378: 449-459.

43. Neelapu SS, Locke FL, Bartlett NL, Lekakis LJ, Miklos DB, et al. (2017) Axicabtagene Ciloleucel CAR T-Cell Therapy in Refractory Large B-Cell Lymphoma. N Engl J of Med 377: 2531-2544.

44. Schuster SJ, Svoboda J, Chong EA, Nasta SD, Mato AR, et al. (2017) Chimeric Antigen Receptor T Cells in Refractory B-Cell Lymphomas. N Engl J of Med 377: 2545-2554.

45. Maude SL, Laetsch TW, Buechner J, Rives S, Boyer M, et al. (2018) Tisagenlecleucel in Children and Young Adults with B-Cell Lymphoblastic Leukemia. N Engl J of Med 378: 439-448.

46. Pan J, Niu Q, Deng B, Liu S, Wu T, et al. (2019) CD22 CAR T-cell Therapy in Refractory or Relapsed B Acute Lymphoblastic Leukemia. Leukemia 33: 2854-2866.

47. Priceman SJ, Tilakawardane D, Jeang B, Aguilar B, Murad JP, et al. (2018) Regional Delivery of Chimeric Antigen Receptor-Engineered T Cells Effectively Targets HER ${ }_{2}{ }^{+}$Breast Cancer Metastasis to the Brain. Clin Cancer Res 24: 95-105.

48. Eudocia Quant Lee (2020) Up-to-date. DMSM. Reed E Drew. MD. Up-to-date, Waltham, MA.

49. Brentjens RJ, Davila ML, Riviere I, Park J, Wang X, et al. (2013) CD19Targeted T Cells Rapidly Induce Molecular Remissions in Adults with Chemotherapy-Refractory Acute Lymphoblastic Leukemia. Sci Transl Med 5: 177ra138. 
50. Hay KA, Turtle CJ (2017) Chimeric Antigen Receptor (CAR) T Cells: Lessons Learned from Targeting of CD19 in B-Cell Malignancies. Drugs 77: 237-245.

51. Santomasso B, Bachier C, Westin J, Rezvani K, Shpall EJ (2019) The Other Side of CAR T-Cell Therapy: Cytokine Release Syndrome, Neurologic Toxicity, and Financial Burden. Am Soc Clin Oncol Educ Book 39: 433-444.

52. David L Porter (2020) Up-to-date. AG Robert S Negrin. MD, Rosmarin. MD. Up-to-date, Waltham, MA.

53. Lee DW, Santomasso BD, Locke FL, Ghobadi A, Turtle CJ, et al. (2019) ASTCT Consensus Grading for Cytokine Release Syndrome and Neurologic Toxicity Associated with Immune Effector Cells. Biol of Blood Marrow Transplant 25: 625-638.

54. Teachey DT, Lacey SF, Shaw PA, Melenhorst JJ, Maude SL, et al. (2016) Identification of Predictive Biomarkers for Cytokine Release Syndrome after Chimeric Antigen Receptor T-cell Therapy for Acute Lymphoblastic Leukemia. Cancer Discov 6: 664-679.

55. Wang Z, Han W (2018) Biomarkers of cytokine release syndrome and neurotoxicity related to CAR-T cell therapy. Biomark Res 6: 4-4.

56. Gofshteyn JS, Shaw PA, Teachey DT, Grupp SA, Maude S, et al. (2018) Neurotoxicity After CTLO19 in a Pediatric and Young Adult Cohort. Ann Neurol 84: 537-546.

57. Gust J, Finney OC, Li D, Brakke HM, Hicks RM, et al. (2019) Glial Injury in Neurotoxicity After Pediatric CD19-Directed Chimeric Antigen Receptor T Cell Therapy. Ann Neurol 86: 42-54.

58. Gust J, GE Ishak (2019) Chimeric Antigen Receptor T-Cell Neurotoxicity Neuroimaging: More Than Meets the Eye. Am J of Neuroradiol 40: E50-E51.

59. Mokhtari S, Arrington J, Asquith J, Bachmeier C, Locke F, et al. (2019) NCMP-13. Brain MRI Findings in Patients Treated With Chimeric
Antigen Receptor T-Cells (CAR-T) During Severe Neurotoxicity Neuro-Oncology 21(Supplement_6): vi181-vi182.

60. Valand HA, Huda F, Tu RK (2019) Chimeric Antigen Receptor T-Cell Therapy: What the Neuroradiologist Needs to Know. Am J Neuroradiol 40: 766-768.

61. Dulamea AO, Lupescu IG (2018) Neurological complications of hematopoietic cell transplantation in children and adults. Neural Regen res 13: 945-954.

62. Singh AK, McGuirk JP (2016) Allogeneic Stem Cell Transplantation: A Historical and Scientific Overview. Cancer res 76: 6445-6451.

63. Nianias A, Themeli M (2019) Induced Pluripotent Stem Cell (iPSC)Derived Lymphocytes for Adoptive Cell Immunotherapy: Recent Advances and Challenges. Curr Hematol Malig Rep 14: 261-268.

64. Silva MC, Haggarty SJ (2019) Human pluripotent stem cell-derived models and drug screening in CNS precision medicine. Annals of the New York Academy of Sciences.

65. Genova E, Cavion F, Lucafò M, Leo L, Pelin M, et al. (2019) Induced pluripotent stem cells for therapy personalization in pediatric patients: Focus on drug-induced adverse events. World J stem cells 11: 1020-1044.

66. Portnow J, Synold TW, Badie B, Tirughana R, Lacey SF, et al. (2016) Neural stem cell-based anti-cancer gene therapy: a first-in-human study in recurrent high-Grade Glioma patients. Clin Cancer Res 23: 2951-2960.

67. Saxena M, Bhardwaj N (2018) Re-Emergence of Dendritic Cell Vaccines for Cancer Treatment. Trends cancer 4: 119-137.

68. Marelli G, Howells A, Lemoine NR, Wang Y (2018) Oncolytic Viral Therapy and the Immune System: A Double-Edged Sword Against Cancer. Front immunol 9: 866. 